\title{
Laparoscopy for Colorectal Malignancy
}

\author{
Stephen H. Pillinger John R.T. Monson \\ The University of Hull, Academic Surgical Unit, Castle Hill Hospital, Cottingham, UK
}

\section{Key Words}

Laparoscopy $\cdot$ Colorectal malignancy $\cdot$ Laparoscopic surgery, indications/contra-indications · Laparoscopic techniques

\begin{abstract}
Laparoscopy for colorectal pathology is technically demanding with a steep learning curve. In expert hands, there is no doubt that there is a place for laparoscopy in the operative armamentarium for the treatment of benign disease. The question of its application in the treatment of carcinoma is more difficult to address. The evidence available suggests that laparoscopic resection is a feasible and appropriate option for the treatment of colorectal carcinoma. The skill and technology to perform the procedure are developing apace, and level 1 evidence to support it is tantalizingly close. This paper will outline the development of the technique, the operative approach, and the available evidence for its use in the treatment of carcinoma.
\end{abstract}

Copyright (C) 2005 S. Karger AG, Basel

\section{Introduction}

It is now over a decade since the first laparoscopic colectomies were performed [1,2]. Large numbers of laparoscopic colorectal procedures have been performed worldwide; however, the adaptation of minimal access techniques to colorectal resection has not proceeded at a rate comparable to that of other areas of general surgery. This may be related to the high degree of laparoscopic skills required, expensive equipment, and protracted operating times. Above all, it is the uncertain oncological safety of laparoscopy that has proven to be the major hurdle to the integration of these techniques into mainstream colorectal practice.

The number of reports of prospective and retrospective audits and case series in peer-reviewed publications is now approaching 100. However, much of this published literature is low in the hierarchy of evidence, with many reports still focusing on the feasibility of the laparoscopic approach. The feasibility of the technique is now not a matter for debate, and most surgeons would agree with its use for benign disease. However, it is still not possible to identify the effectiveness, safety, benefits, and survival outcome in the long term, or cost of laparoscopic surgery for colorectal malignancy in comparison to open surgery. This reflects a lack of control following the introduction of this new technology. The Clinical Outcomes of Surgical Therapy Study Group (COST) from the USA have recently published their randomized trial [3], showing the laparoscopic approach is an acceptable alternative to open surgery. There are large prospective trials under way in Europe, Scandinavia, and Australasia [4, 5]. These trials will hopefully provide the level 1 evidence to definitively answer the above questions.

\section{KARGER \\ Fax +4161306 1234 E-Mail karger@karger.ch} www.karger.com
Prof. J.R.T. Monson, Head

The University of Hull, Academic Surgical Unit

Castle Hill Hospital, Castle Road

Cottingham HU16 5JQ (UK)

Tel. +44 1482623 247, Fax +44 1482623 274, E-Mail J.R.Monson@hull.ac.uk 
The operative techniques are evolving with the technology. The pace of change regarding the technology is something that other authors have also noted [6], and it is another factor that makes interpretation of the existing data difficult. Essentially a laparoscopic colorectal resection in 2004 is a completely different procedure to one performed in 1994. For example, many more resections are now completed entirely laparoscopically, particularly left colon and rectal resections. Small incisions are still required for specimen delivery and often to perform the anastomosis; however, these are no longer 'laparoscopicassisted' procedures.

\section{Indications and Contra-Indications}

Surgery remains the principal treatment for colorectal cancer, with the cure and survival rates directly related to the standard of surgery [7-9]. Many surgeons remain skeptical regarding the suitability of laparoscopic surgery for curative resection of colon cancer. Anxiety levels in this regard may be multiplied several times when the issue of a laparoscopic approach to rectal cancer is contemplated. Excellence in surgical technique is of particular relevance to the treatment of rectal cancer, as routine excision of the intact mesorectum during resection of cancers of the mid and lower rectum has resulted in the lowest incidence of local recurrence reported [10]. There are a number of concerns such as the ability of the laparoscopic approach to allow a precise total mesorectal excision, as championed by Heald and Ryall [11]. Such concerns are appropriate; however, studies to date have consistently failed to demonstrate any detriment in terms of disease recurrence and survival consequent to a laparoscopic approach to colorectal cancer [12-17].

Unless there are specific contra-indications, most patients should be considered candidates for a laparoscopic approach, provided the equipment and surgical expertise are available [18]. Debate continues as to whether malignancy itself should represent an absolute contra-indication. Apart from perforation and obstructing carcinoma, there are no uniformly accepted specific contra-indications. Cancers of the transverse colon, palpable cancers, and those invading adjacent viscera are probably not appropriate for a laparoscopic approach [19]. It must be remembered that around $20-30 \%$ of the patients with colorectal cancer will have stage IV disease at the time of presentation. This group of patients may provide an ideal indication for laparoscopic resection, because the potential benefits for laparoscopy may be the most appli- cable, and concerns over compromised chances of achieving a curative resection are of less relevance. Milsom et al. [20] reported the Cleveland Clinic experience with palliative laparoscopic surgery. Thirty patients with stage IV colorectal cancer underwent a laparoscopic procedure $16 \mathrm{had}$ a resection, 11 underwent palliative stoma formation, and 3 were converted to formal laparotomy. Two patients who had stoma formation alone died during the same admission. There were no operative complications. The authors concluded that laparoscopy may facilitate effective palliation in selected patients, with the avoidance of a major laparotomy.

Laparoscopic stoma formation has a number of potential advantages over conventional techniques of ostomy formation $[21,22]$. It is often easier to orientate the afferent limb in the formation of a loop colostomy, when compared to standard trephine technique. There is no need for a significant abdominal incision. This is an important consideration in the case of carcinoma of rectum or anal canal, where defunctioning is required prior to chemoradiotherapy. These patients can commence their treatment far more quickly after laparoscopic defunctioning [23].

The other obvious application for laparoscopy in colorectal malignancy would be staging. However, it seems unlikely that the use of laparoscopy for staging colorectal cancer will approach that of staging upper gastro-intestinal malignancy [24, 25]. Digital rectal examination, transanal ultrasound, and cross-sectional imaging in combination almost always provide enough information for adequate decision-making regarding the need for neoadjuvant chemoradiotherapy. Technical operability can also be determined in the majority of the cases with crosssectional imaging.

Extensive intraperitoneal adhesions and obesity represent relative contra-indications. An open technique for cannula insertion should be used for those patients who have had previous abdominal surgery. The laparoscopic approach is intolerant of cases that are difficult due to adhesions, obesity, or bulky or fixed tumours. There has to be a low threshold for conversion in these patients. Inability to identify the ureters, doubtful resectability, and equipment failure are other reasons to consider conversion. There is certainly a significant and protracted learning curve associated with laparoscopic colorectal surgery. The learning curve of any procedure is notoriously difficult to quantify [26, 27], and the above factors must be evaluated for each individual patient. One interesting article with implications for future training has been published [28], indicating fellowship training in laparoscopic 
colorectal surgery may make learning curve issues redundant in early practice.

\section{Technical Aspects}

Excellent detailed accounts of the techniques for laparoscopic colorectal resection are readily available in the literature [29-31]. We will review the important principles here. Firstly, the patients must be prepared in the same way as for open resection. They must be fully counseled and informed consent obtained for laparotomy. Secondly, the surgeon must be absolutely clear as to the location of the lesion. It is sometimes very difficult to determine exactly where it is laparoscopically due to the lack of tactile information. This is especially true if there is no serosal involvement, or the tumour lies posteriorly or below the peritoneal reflection. Intra-operative colonoscopy is time-consuming and cumbersome in this setting and can make further laparoscopic dissection impossible because of colonic distension [32]. Tattooing at the time of colonoscopy helps around 50\% of the time [33], but in the remaining 50\% there is either no obvious ink at laparoscopy or ink spread around the abdominal cavity. Handassisted laparoscopic surgery may provide the necessary tactile information; however it is a technique that has not been evaluated by means of a large-scale randomized trial, has not been shown to offer additional benefits to conventional laparoscopic techniques, and is not widely employed.

Pre-operative tumour localization is therefore vital. Unfortunately, small lesions that are difficult to detect laparoscopically may also not be well localized by barium enema, and even with expert colonoscopists there can be a discrepancy of up to one colonic flexure in tumour localization [34]. Where doubt exists, the colonoscopist is best advised to use X-ray imaging at the time of colonoscopy or place clips adjacent to the tumour to allow accurate localization with an intra-operative image intensifier. With a rectal cancer, there is no true facility for trial dissection with laparoscopy to 'see if the tumour comes up', and therefore the surgeon must be certain that an abdominoperineal excision, if planned, is required and not an anterior resection.

The principal steps in laparoscopic colorectal resection are identical to those in the open procedure and comprise: (1) mobilization of the bowel, (2) division of the vascular pedicle and lymphadenectomy, (3) resection of the involved segment, and (4) restoration of continuity or stoma formation. Attention to haemostasis must be ab- solute, and in this regard, there are certainly two instruments we consider indispensable. The harmonic scalpel allows for precise, haemostatic dissection without the smoke plume generated by diathermy. Secondly the articulating endoscopic GIA staplers (Auto Suture Endo GIA; Tyco Healthcare, Norwalk, Conn., USA) allow a high division of the vascular pedicles and, with the articulating head, low rectal division. Babcock-type bowelgrasping forceps are used for manipulating the bowel.

Full video-endoscopic facilities are required. Our preference is to have two monitors, one on either side of the patient at shoulder level, to ensure that a screen is readily visible to surgeon, assistant, and scrubbed nurse. Port placement is a balance between the individual surgeon's preference, the need to access several abdominal regions, and the patient's body habitus. Therefore, there is no 'ideal' arrangement.

\section{Conversion}

The reasons for conversion to an open procedure are outlined above. When reviewing the literature, analysis of the need for conversion is hindered by the fact that few series provide a definition for conversion, nor do they provide detailed reasons for conversion. We would suggest that a reasonable working definition would be the enforced or elective requirement for an unplanned incision or one that was longer or made earlier than had been intended. Conversion is more likely with left-sided and rectal dissections, and the rates do appear to reduce with experience. Rates ranging from 1.45 to $48 \%$ have been reported, with a mean conversion rate for collated series of around $17.5 \%$ [see 12, 14, 46, 56, 57, 59]. It is important that patients are counseled appropriately.

\section{Outcomes}

Carcinoma of colon and rectum is the only commonly curable visceral malignancy. In the United Kingdom, half the patients presenting with the disease are treated with a reasonable expectation of cure. Approximately half of these can expect to be alive 5 years later $[9,35]$. Traditional surgical principles are often based more on doctrine rather than science. For example, no study has ever shown that a 'high ligation' of the inferior mesenteric artery (and, therefore, a radical lymphadenectomy) carries any survival advantage over 'low ligation' below the origin of the left colic artery [36, 37]. The number of lymph 
nodes detected in a resection specimen is also dependent on the diligence of the pathologist and the method of preparation of the specimen [38]. The finding that a minimum number of lymph nodes (from 12 to 17 ) is necessary for adequate assessment of disease clearance and stage [39-41] is countered by other studies that show that whilst nodal status is an indicator of survival, it is not a good predictor of clinical outcome [42, 43]. Despite this, the standards that are set at open surgery are those against which laparoscopic resection must be judged.

The rectum can certainly be excised with an intact mesorectal fascial envelope all the way down to the level of the pelvic floor. It is our firm belief that an ability to perform rectal dissection laparoscopically helps with the open procedure, as the clarity of the view even at the pelvic floor shows precisely the planes of dissection. It is well established that the widest possible radial tumour clearance should be undertaken with rectal cancer, as the presence of histologically positive circumferential resection margins is associated with rates of local recurrence in excess of $80 \%[44,45]$. We have shown previously that it is feasible to perform a totally laparoscopic excision of the mesorectum, in a cohort study comparing laparoscopic with open excision [14]. A single colorectal pathologist, blind to the method of resection, assessed all the specimens according to the standard techniques, as described by Quirke et al. [44]. There was no difference between the groups for the histologic parameters of specimen length, circumferential margin, and lymph node yield. These are all, rightly or wrongly, taken as measures of a radical rectal dissection. Parity in these parameters between laparoscopic and open surgery has been demonstrated by other investigators $[12,13,15-17,46-55]$. A laparoscopic dissection can, therefore, fulfil these requirements.

A fairly uniform finding among reported series is that laparoscopic colorectal procedures almost invariably take longer than the comparable open procedure [12, 46, 5659]. The operating times are reduced with progress along the learning curve, and, importantly, they may approach the surgeon's own times for the corresponding open procedure. Rather than a blanket comparison with all surgeons, the goal of the laparoscopist should be to perform the procedure with the same skill and at the same pace, as he/she would perform the open procedure.

Laparoscopic colorectal resection can be performed safely. There is a notable lack of quality-of-life studies [60]; however, there are undoubted benefits for patients in terms of faster recovery of pulmonary and gastro-intestinal function, cosmesis, reductions in analgesic requirements, and modest reductions in hospital stay.
These benefits may be small, but they have again been shown in the recent COST trial [3]. It is noteworthy that this trial compared only straightforward left and right colonic resections, not transverse colon or rectal disease. Therefore, the results are not applicable to the full range of laparoscopic colorectal surgery. However, it is unlikely that further improvements in these outcomes will be seen, as they are largely the result of total operative trauma. For radical colorectal resection, a laparotomy wound, although important, represents a lesser proportion of the total operative trauma which usually involves at least two abdominal quadrants, and in rectal cancer an extensive pelvic dissection $[6,61]$. Therefore, the reduction in the size of the wounds has led to a reasonably modest reduction in postoperative morbidity. There may be further modest improvements in pain scores and lengths of stay, as more laparoscopic as opposed to 'laparoscopic-assisted' resections are performed. Major morbidity is unlikely to be reduced. The anastomotic leak rate appears to have reached parity with open surgery, and there is no reason to suspect it will be further lowered. Operative mortality appears unaffected. From the limited data available, it is impossible to draw firm conclusions regarding cancer-specific survival and local recurrence rates, but they would appear to be comparable to open surgery [62]. Our own prospective controlled trial of laparoscopic versus open surgery [63] showed no significant difference in the incidence of local or systemic recurrence. We have also found no difference in long-term survival [64].

There is limited data on long-term survival and disease recurrence. The COST trial [3] has a median follow-up period of 4.4 years, with no significant differences between the open and laparoscopic groups in time to recurrence, disease-free survival, or overall survival for any stage of disease. The Norfolk group [65] have presented 24-month follow-up data, with a cancer-specific mortality of $6 \%$ and an overall recurrence rate of $9 \%$. The 3-year actuarial survival was $92 \%$ for node-negative and $79 \%$ for node-positive patients. Lumley et al. [26] reported a recurrence rate of $6.3 \%$ at a median follow-up time of 33 months and Gray et al. [66] a rate of $23 \%$ of 22 patients followed for 24 months. Five-year survival rates have recently been reported by Lujan et al. [67]: 73\% for stage I, $61 \%$ for stage II, $55 \%$ for stage III, and $0 \%$ for stage IV. These rates are comparable to the authors' own for open resections and to the stage-specific rates of the National Cancer Data Base (NCDB) of the American College of Surgeons Commission on Cancer. The spectre of port-site metastases has faded, with none in any of the above series. 


\section{Complications}

There are well-documented complications that are specific to laparoscopy. These are for the most part avoidable with good technique. The contention that Verres needle injuries can be avoided by employing an open technique is not backed up by the literature, and we continue to use a Verres needle for introduction of pneumoperitoneum, unless there has been previous abdominal surgery. Trocar injuries are avoided by ensuring that all subsequent ports are introduced under direct vision. Port-site herniation can be largely prevented by the meticulous closure of all port sites $>10 \mathrm{~mm}$. Operative complications such as major haemorrhage, inadvertent enterotomy, ureteral injury, and major vessel laceration have all been reported, with rates ranging from 0 to $12 \%[6,12$, $14,46,51,56,57,59]$. The overall morbidity rate is between 6 and 39\% [59, 68-77].

Postoperative complications are broadly comparable to those that are seen in open surgery. The anastomotic leak rates in the larger series are around $10 \%$, and our experience is consistent with this figure [78-80]. The high incidence of thrombo-embolic complications reported in one early series [49] has not been reported in more recent series. The potential for fewer abdominal adhesions in comparison with open surgery is a factor that has been perhaps underreported, and it may have important patient and financial implications. One large study with long-term follow-up [19] has reported a rate of adhesive obstruction after major laparoscopic resectional surgery of only $3 \%$.

\section{Conclusions}

Laparoscopic colorectal surgery is technically demanding, with a significant learning curve. The technique is intolerant of difficult cases and will likely remain thus. Through weight of evidence (and despite the lack of level 1 evidence), its use in the treatment of benign disease is beyond question. However, for colorectal malignancy, it is not possible to make a general recommendation at the present time. The goals of colorectal cancer treatment remain fewer stomas, low rates of local recurrence, and low rates of autonomic nerve damage in rectal excision. For the future to these aims should be added smaller incisions, rapid recovery of gastro-intestinal function, and early discharge from hospital. From the available data, there is no doubt that laparoscopic resection is feasible, can be performed safely with similar morbidity and mortality rates when compared to open surgery, and satisfies the histological parameters for a radical resection. The approach also offers the possibility of achieving the other aspirations increasingly recognized as important.

It is a sobering reality that no major surgical intervention has ever been introduced on the basis of a large-scale randomized controlled trial. All is not lost however, as the COST trial [3] shows. Other large trials are ongoing around the world and should report within a few years. Hopefully at that time a general recommendation for laparoscopic resection for colorectal cancer can be made. Until then, we would agree with other authors [81, 82] that it should only be performed within the confines of a trial, and by expert hands.

\section{References}

1 Corbitt JD Jr: Preliminary experience with laparoscopic-guided colectomy. Surg Laparosc Endosc 1992;2:79-81.

-2 Fowler DL, White SA, Anderson CA: Laparoscopic colon resection: 60 cases. Surg Laparosc Endosc 1995;5:468-471.

-3 Clinical Outcomes of Surgical Therapy Study Group: A comparison of laparoscopically assisted and open colectomy for colon cancer. $\mathrm{N}$ Engl J Med 2004;350:2050-2059.

-4 Stocchi L, Nelson H: Laparoscopic colectomy for colon cancer: Trial update. J Surg Oncol 1998;68:255-267.

5 Wittich P, Kazemier G, Schouten WR: The 'Colon Cancer Laparoscopic or Open Resection' (COLOR) Trial (in Dutch). Ned Tijdschr Geneeskd 1997;141:1870-1871.
6 Milsom JW, Bohm B, Hammerhofer KA, Fazio V, Steiger E, Elson P: A prospective, randomized trial comparing laparoscopic versus conventional techniques in colorectal cancer surgery: A preliminary report. J Am Coll Surg 1998; 187:46-54

7 Cady B: Lymph node metastases: Indicators but not governors of survival. Arch Surg 1984; 119:1067-1072.

8 McArdle CS, Hole D: Impact of variability among surgeons on postoperative morbidity and mortality and ultimate survival. BMJ 1991;302:1501-1505.

-9 Phillips RK, Hittinger R, Blesovsky L, Fry JS, Fielding LP: Local recurrence following 'curative' surgery for large bowel cancer. I. The overall picture. Br J Surg 1984;71:12-16.
10 MacFarlane JK, Ryall RD, Heald RJ: Mesorectal excision for rectal cancer. Lancet 1993; 341:457-460.

11 Heald RJ, Ryall RD: Recurrence and survival after total mesorectal excision for rectal cancer. Lancet 1986;1:1479-1482.

12 Stage JG, Schulze S, Möller P: Prospective randomized study of laparoscopic versus open resection for adenocarcinoma. Br J Surg 1997; 84:391-396.

13 Lord SA, Larach SW, Ferrara A: Laparoscopic resections for colorectal carcinoma: A threeyear experience. Dis Colon Rectum 1996;39: 148-154.

14 Hartley JE, Mehigan BJ, Monson JR: Total mesorectal excision: Assessment of the laparoscopic approach. Dis Colon Rectum 2001;44: 315-321. 
-15 Lacy AM, Delgado S, Garcia-Valdecasas JC, Castells A, Pique JM, Grande L, Fuster J, Targarona EM, Pera M, Visa J: Port site metastases and recurrence after laparoscopic colectomy: A randomized trial. Surg Endosc 1998;12: 1039-1042.

16 Buchmann P, Christen D: Pro laparoscopic surgery for colorectal cancer. Dig Dis 1995; 12 : 296-301.

17 Gellman L, Salky B, Edye M: Laparoscopic-assisted colectomy. Surg Endosc 1996;10:10411044.

18 Fielding GA, Lumley J, Nathanson L: Laparoscopic colectomy. Surg Endosc 1997;11:745749.

19 Lumley J, Stitz R, Stevenson A, Fielding G, Luck A: Laparoscopic colorectal surgery for cancer: Intermediate to long-term outcomes. Dis Colon Rectum 2002; 45:867-872.

20 Milsom JW, Kim SH, Hammerhofer KA: Laparoscopic colorectal cancer surgery for palliation. Dis Colon Rectum 2000;43:1512-1516.

-21 Lange V, Meyer G, Schardey HM, Schildberg FW: Laparoscopic creation of a loop colostomy. J Laparoendosc Surg 1991;1:307-312.

-22 Duh QY, Way LW: Diagnostic laparoscopy and laparoscopic cecostomy for colonic pseudo-obstruction. Dis Colon Rectum 1993;36: 65-70.

23 Koea JB, Guillem JG, Conlon KC: The role of laparoscopy in the initial multimodality management of patients with near-obstructing rectal cancer. J Gastrointest Surg 2000;4:105108.

24 Cuesta MA, Meijer S, Borgstein PJ: Laparoscopy and the assessment of digestive tract cancer. Br J Surg 1992;79:486-487.

-25 Watt I, Stewart I, Anderson D: Laparoscopy, ultrasound and computed tomography in cancer of the oesophagus and gastric cardia: A prospective comparison for detecting intra-abdominal metastases. Br J Surg 1989;76: 1036-1039.

-26 Lumley J, Fielding G, Rhodes M, Nathanson L, Siu S, Stitz R: Laparoscopic assisted colorectal surgery: Lessons learned from 240 consecutive patients. Dis Colon Rectum 1996;39:155159.

-27 Wishner JD, Baker JW Jr, Hoffman GC, Hubbard GW 2nd, Gould RJ, Wohlgemuth SD, Ruffin WK, Mellick CF: Laparoscopic-assisted colectomy - the learning curve. Surg Endosc 1995;9:1179-1183.

>28 Schlachta CM, Mamazza J, Gregoire R, Burpee SE, Pace KT, Poulin E: Predicting conversion in laparoscopic colorectal surgery: Fellowship training may be an advantage. Surg Endosc 2003; 17:1288-1291.

-29 Elftmann TD, Nelson H, Ota DM: Laparoscopic-assisted segmental colectomy: Surgical techniques. Mayo Clin Proc 1994;69:825833.

30 Monson JR, Darzi A: Laparoscopic Colorectal Surgery. Oxford, Isis Medical Media, 1995.

>31 Darzi A, Hill AD, Henry MM, Guillou PJ, Monson JR: Laparoscopic assisted surgery of the colon: Operative technique. Endosc Surg Allied Technol 1993;1:13-15.
32 Luck AJ, Thomas ML, Roediger WE, Hewett PJ: Localization of the nonpalpable colonic lesion with intraoperative ultrasound. Surg Endosc 1999; 13:526-527.

33 Kitamura K, Yamane T, Oyama T: Rapid and accurate method for delineating cancer lesions in laparoscopic colectomy using activated carbon injection. J Surg Oncol 1995;58:31-34.

34 Lam DT, Kwong KH, Lam CW, Leong HT, Kwok SP: How useful is colonoscopy in locating colorectal lesions? Surg Endosc 1998;12: 839-841.

35 Phillips RK, Hittinger R, Blesovsky L, Fry JS, Fielding LP: Local recurrence following 'curative' surgery for large bowel cancer. II. The rectum and rectosigmoid. Br J Surg 1984;71:1720.

36 Surtees P, Ritchie JK, Phillips RK: High versus low ligation of the inferior mesenteric artery in rectal cancer. Br J Surg 1990;77:618-621.

37 Pezim ME, Nicholls RJ: Survival after high or low ligation of the inferior mesenteric artery during curative resection for rectal cancer. Ann Surg 1984;200:729-733.

-38 Nduka CC, Monson JR, Menzies-Gow N, Darzi A: Abdominal wall metastases following laparoscopy. Br J Surg 1994;81:648-652.

39 Fine AP, Lanasa S, Gannon MP, Cline CW, James R: Laparoscopic colon surgery: Report of a series. Am Surg 1995;61:412-416.

40 Golub R, Golub RW, Cantu R Jr, Stein HD: A multivariate analysis of factors contributing to leakage of intestinal anastomoses. J Am Coll Surg 1997;184:364-372.

41 Semm K: Endoscopic appendectomy. Endoscopy 1983;15:59-64.

42 Cancer Research Campaign: Cancer of the Large Bowel. London, Cancer Research Campaign, 1993. (From mortality statistics: Causes England and Wales 1991. London, HMSO, Annual Report of the Registrar General for Scotland 1991 and unpublished statistics for the Registrar General's Office for Northern Ireland.)

43 Trokel MJ, Bessler M, Treat MR, Whelan RL, Nowygrod W: Preservation of immune response after laparoscopy. Surg Endosc 1994;8: 1385-1388.

44 Quirke P, Durdey P, Dixon MF, Williams NS: Local recurrence of rectal carcinoma due to inadequate surgical resection: Histopathological study of lateral tumour spread and surgical excision. Lancet 1986;2:996-999.

45 Adam IJ, Mohamdee MO, Quirke P: Role of circumferential margin involvement in the local recurrence of rectal cancer. Lancet 1994; 344:707-711.

46 Monson J, Darzi A, Carey P: Prospective evaluation of laparoscopic-assisted colectomy in an unselected group of patients. Lancet 1992;340: 831-833.

47 Hoffman G, Baker J, Fitchett C: Laparoscopicassisted colectomy: Initial experience. Ann Surg 1994;219:732-743.

48 Falk PM, Beart RW Jr, Wexner SD: Laparoscopic colectomy: A critical appraisal. Dis Colon Rectum 1993;36:28-34.
49 Guillou P, Darzi A, Monson J: Experience with laparoscopic colorectal surgery for malignant disease. Surg Oncol 1993;2(Suppl 1):43-49.

50 Van Ye TM, Cattey RP, Henry LG: Laparoscopically assisted colon resections compare favourably with open technique. Surg Laparosc Endosc 1994;4:25-31.

51 Chapman AE, Levitt MD, Hewett P, Woods R, Sheiner H, Madden GJ: Laparoscopic-assisted resection of colorectal malignancies - a systematic review. Ann Surg 2001;234:590_ 606.

52 Greene FL: Laparoscopic management of colorectal cancer. CA Cancer J Clin 1999;49: 221-228.

53 Lee SW, Gleason NR, Whelan RL: Laparoscopic resection for colorectal cancer - is it justified? Surg Oncol Clin N Am 2000;9:763781.

>54 Leung KL, Kwok SP, Lau WY: Laparoscopicassisted resection of rectosigmoid carcinoma: Immediate and medium-term results. Arch Surg 1997; 132:761-764.

55 Rickard MJ, Bokey EL: Laparoscopy for colon cancer. Surg Oncol Clin N Am 2001;10:579597.

$>56$ Lacy AM, Garcia-Valdecasas JC, Pique JM: Short-term outcome analysis of a randomized study comparing laparoscopic versus open colectomy for colon cancer. Surg Endosc 1995;9: 1101-1105.

57 Hewitt PM, Ip SM, Kwok SP: Laparoscopicassisted vs. open surgery for colorectal cancer: Comparative study of immune effects. Dis Colon Rectum 1998;41:901-909.

58 Phillips E, Franklin M, Carroll B: Laparoscopic colectomy. Ann Surg 1992;216:703-707.

59 Fleshman JW, Nelson H, Peters WR, et al: Early results of laparoscopic surgery for colorectal cancer: Retrospective analysis of 372 patients treated by Clinical Outcomes of Surgical Therapy (COST) Study Group. Dis Colon Rectum 1996;39(10 Suppl):S53-S58.

60 Weeks JC, Nelson H, Gelber S, Sargent D, Schroeder G; Clinical Outcomes of Surgical Therapy (COST) Study Group: Short-term quality-of-life outcomes following laparoscopic-assisted colectomy vs open colectomy for colon cancer: A randomized trial. JAMA 2002; 287:321-328.

61 Monson JR, Hill AD, Darzi A: Laparoscopic colonic surgery. Br J Surg 1995;82:150-157.

62 Patankar SK, Larach SW, Ferrara A: Prospective comparison of laparoscopic vs. open resections for colorectal adenocarcinoma over a tenyear period. Dis Colon Rectum 2003;46: 601-611.

63 Hartley JE, Mehigan BJ, Monson JR: Patterns of recurrence and survival after laparoscopic and conventional resections for colorectal carcinoma. Ann Surg 2000;232:181-186.

64 Baker RP, White EE, Monson JR: Does laparoscopic abdominoperineal resection of the rectum compromise long-term survival? Dis Colon Rectum 2002;45:1481-1485. 
-65 Hoffman GC, Baker JW, Doxey JB, Hubbard GW, Ruffin WK, Wishner JA: Minimally invasive surgery for colorectal cancer: Initial follow-up. Ann Surg 1996;223:790-798.

-66 Gray D, Lee H, Schlinkert R, Beart RW Jr: Adequacy of lymphadenectomy in laparoscopic-assisted colectomy for colorectal cancer: A preliminary report. J Surg Oncol 1994;57:810.

-67 Lujan HJ, Plasencia G, Jacobs M, Viamonte M 3rd, Hartmann RF: Long-term survival after laparoscopic colon resection for cancer: Complete five-year follow-up. Dis Colon Rectum 2002;45:491-501.

68 Agachan F, Joo JS, Sher M, Weiss EG, Nogueras JJ, Wexner SD: Laparoscopic colorectal surgery: Do we get faster? Surg Endosc 1997; 11:331-335.

69 Agachan F, Joo JS, Weiss EG, Wexner SD: Intraoperative laparoscopic complications: Are we getting better? Dis Colon Rectum 1996; 39(10 suppl):S14-S19.
70 Baca I, Schultz C, Götzen V, Grzybowski L: Laparoscopy-assisted colorectal surgery: Early outcome in benign and malignant diseases - a prospective study of 120 patients (in German). Zentralbl Chir 1997;122:569-577.

71 Fleshman JW, Fry RD, Birnbaum EH, Kodner IJ: Laparoscopic-assisted and minilaparotomy approaches to colorectal diseases are similar in early outcome. Dis Colon Rectum 1996;39: $15-22$.

72 Hoffman GC, Baker JW, Fitchett CW, Vansant JH: Laparoscopic-assisted colectomy - initial experience. Ann Surg 1994;219:732-743.

73 Köckerling F, Scheidbach H, Schneider C: Laparoscopic abdominoperineal resection: Early postoperative results of a prospective study involving 116 patients. Dis Colon Rectum 2000;43:1503-1511.

74 Larach SW, Patankar SK, Ferrara A, Williamson PR, Perozo SE, Lord AS: Complications of laparoscopic colorectal surgery: Analysis and comparison of early vs. later results. Dis Colon Rectum 1997;40:592-596.

75 Reissman P, Cohen SM, Weiss EG, Wexner SD: Laparoscopic colorectal surgery: Ascending the learning curve. World J Surg 1996;20 277-282.
76 Wexner SD, Cohen SM, Ulrich A, Reissman P: Laparoscopic colorectal surgery: A prospective assessment and current perspective. $\mathrm{Br} \mathrm{J}$ Surg 1993;80:1602-1605.

77 Wu JS, Birnbaum EH, Fleshman JW: Early experience with laparoscopic abdominoperineal resection. Surg Endosc 1997;11:449-455.

78 Fielding GA, Lumley J, Nathanson L: Laparoscopic colectomy. Surg Endosc 1997;11:745749.

79 Yong L, Deane M, Monson JR: Systematic review of laparoscopic surgery for colorectal malignancy. Surg Endosc 2001;15:1431-1439.

80 Scheidbach H, Schneider C, Konradt J: Laparoscopic abdominoperineal resection and anterior resection with curative intent for carcinoma of the rectum. Surg Endosc 2002;16: $7-13$.

81 da Silva G, Borjesson L, Wexner S: Laparoscopy for colorectal cancer. Semin Laparosc Surg 2004; 11:3-12.

82 Scheidbach H, Kockerling F: Laparoscopy for rectal carcinoma: Abdominoperineal excision. Semin Laparosc Surg 2004;11:19-22. 